\title{
Commentary on this special issue of Advances in Audit Analytics
}

\author{
Deniz Appelbaum ${ }^{1}$
}

Received: 30 July 2019 / Published online: 29 August 2019

(c) Springer Nature Limited 2019

Recently, the IJDG announced that it would soon publish a special issue on Advances in Audit Analytics, with a combination of papers from audit practitioners and researchers from a domestic and international perspective. Theoretical and practical perspectives of audit analytics and recent innovations in technology on financial reporting, compliance, disclosure, and governance were encouraged. This IJDG special issue would balance this discussion of audit analytics between academic discussions and practical applications in real life. Coverage of audit analytics could range across the landscape of enterprise, from public corporations to closely held companies, and to municipalities.

The papers in this special issue on Advances in Audit Analytics deal with this pressing challenge: How is the profession responding to the innovations of analytics and technology in business and government? Since technology permeates almost every aspect of business and government these days, is accounting practice keeping pace? Are auditors of municipalities and businesses deploying the latest analytics? This issue presents five discussions by expert academics and business professionals and covers such topics as data transparency in e-governments, blockchain, AI, analytics of unregulated corporate disclosures, and the potential for increased use of analytics for fraud detection. A more detailed view of these papers is as follows:

Practitioners Bhatt and Fagan (2019) point out that in the current business environment, it's not enough to make sure that businesses are compliant-auditing as a function has an opportunity to help enterprises address issues that impact a businesses' operational performance. Artificial intelligence-based techniques have improved to the point that machines can now address inherently human problems. So, if machines have been able to do the tedious tasks that auditors can do, then what becomes more valuable? An auditor's judgement becomes more valuable as the outcome and

Deniz Appelbaum

appelbaumd@montclair.edu

1 Montclair, NJ, USA action based on the analysis still depend on them. Like many long-established professions, artificial intelligence is transforming the audit industry.

McAliney and Ang (2019) revisit two existing technologies - the more traditional relational database and a newer solution, Google Sheets-for storing and sharing data over the network, and their applicability to meeting an accountanting organization's business needs. These two technologies, along with blockchain, are evaluated against a set of criteria that are essential to most business operations. Decision makers can use this framework that identifies the capabilities and shortfalls of each of these technologies to inform the most effective and appropriate technological solution for individual business opportunities. Further, the paper will address the implications on how an organization addresses data governance. Lastly, a decision paradigm, based on an established set of criteria, is presented to guide an accounting organization in choosing the most appropriate technology. In other words, no single one technology will provide the solution for all business problems.

Michael and Dixon (2019) are concerned with the usefulness of using audit data analytics of unregulated voluntary disclosures in reducing the auditing expectations gap. They argue that the lack of credibility and assurance of the unstructured voluntary disclosures and other big data will impact the level of public users' expectations towards the quality of these unregulated voluntary disclosures. Therefore, they argue that non-financial, as well as financial; data require assurance by an independent auditor. Consequently, this would expand the auditors' role and responsibilities which will lead to raising the degree of stakeholders' satisfaction and approaching their expectations, potentially reducing the auditing expectations gap. Auditors will need to rely more heavily on big data analytics and technological techniques to perform this new role efficiently and effectively. Therefore, they provide empirical evidence that the perceptions of auditors, bankers, investors, and academics support the use of audit data analytics when providing assurance of unregulated voluntary disclosures in reducing auditing expectations gap. To do so, they categorize unregulated 
voluntary disclosures into eight different categories that audit data analytics is required in an informative and useful fashion.

Alzamil and Vasarhelyi (2019) describe how Open Government Data (OGD) is attracting stakeholders from different backgrounds. The call for OGD has been especially pronounced in the last six or seven years. Publishing government data, thereby making it available to the public, could be useful in many ways such as increasing transparency and accountability in governments, increasing overall efficiency and performance, encouraging publics' engagement, and achieving trust and reputation. As an example of the role that OGD may provide, this paper compares the different financial reporting and auditing systems in the public sector between Brazil and Saudi Arabia. Also, the paper examines open government data initiatives among different countries with the focus of the Republic of Brazil and the Kingdom of Saudi Arabia's open data portals. Moreover, it assesses the level of data transparency based on the definition of the open data model, and more importantly, the paper suggests new dimensions to the open data concept when utilized by governments. In addition, it argues that the open government data in Saudi Arabia, which is an emerging initiative in a country that has centralized power, could be improved dramatically. We demonstrate that by using a sample of procurement contracts data taken from the Council of Saudi Chambers website, which is publicly available and shows the potential of monitoring or auditing public spending.

Albizri and Appelbaum (2019) posit that prior research in the fields of accounting, information systems, and analytics has shed light on the significant effects of financial reporting fraud on multiple levels of economy. In this paper, they compile multidisciplinary literature on financial statements fraud detection. They feel that financial reporting fraud detection efforts and research may be more impactful when the findings of these different domains are combined. When combined, it is clear that there exists great variance between domains in the literature. That is, the indicators of accounting and information systems rarely match in their terms and in materiality for fraud prediction. Such disparity might be explained due to the different methods or research, where accounting has been more domain focused, innovative in terms of indicator discovery, and based in historical data, whereas information systems are more process oriented focusing on improving fraud detection model results by innovative business analytics techniques and machine learning algorithms. The question remains as to whether one domain is more "accurate" for fraud prediction or not and whether any other metrics outside of AAER's have been proposed. More important is that new studies should integrate techniques from both fields as well as benefit and build upon literature from both disciplines.

In conclusion, these papers review the challenges posed by technology and analytics to the accounting and auditing professions, from a global perspective. Clearly, the greatest risk to the profession is its slow ability to digest and integrate new technologies and approaches, due to regulatory restrictions. Academics may want to revamp their audit curricula to encourage analytics skills development. Researchers may want to examine many of the issues brought forth within these papers, to expand their potential impact on the auditing profession. Overall, researchers have an obligation to work with analytics in such a way that would improve the general understanding of how technology can improve the audit process. As such, these papers are of great benefit to auditors, analysts, regulators, and the general public.

\section{References}

Albizri, A., and D. Appelbaum. 2019. Evaluation of financial statements fraud detection research: A multi-disciplinary analysis. International Journal of Disclosure and Governance. https://doi. org/10.1057/s41310-019-00067-9.

Alzamil, Z.S., and M.A. Vasarhelyi. 2019. A new model for effective and efficient open government data. International Journal of Disclosure and Governance. https://doi.org/10.1057/s4131 0-019-00066-w.

Bhatt, D., and J. Fagan. 2019. Artificial intelligence: Redefining human potential in audit. International Journal of Disclosure and Governance. https://doi.org/10.1057/s41310-019-00063-z.

McAliney, P., and B. Ang. 2019. Blockchain: business' next new "It" technology - a comparison of blockchain, relational databases, and Google Sheets. International Journal of Disclosure and Governance. https://doi.org/10.1057/s41310-019-00064-y.

Michael, A., and R. Dixon. 2019. Audit data analytics of unregulated voluntary disclosures and auditing expectations gap. International Journal of Disclosure and Governance. https://doi.org/10.1057/ s41310-019-00065-x.

Publisher's Note Springer Nature remains neutral with regard to jurisdictional claims in published maps and institutional affiliations. 